\title{
REPORT OF A WORKSHOP
}

\section{Aerosol therapy in the newborn}

\author{
M Silverman
}

\section{Background}

Therapeutic aerosols have been used for many years in the management of disorders of the respiratory tract in both adults and children. Only recently have they been considered for the treatment of respiratory disorders of newborn infants. Several important questions concerning the use of therapeutic aerosols in infants were discussed at a workshop attended by 24 paediatricians and aerosol scientists from Europe, North America, and Australia (Royal Postgraduate Medical School, London; 7-8 December 1989).

- Are lung disorders in newborns likely to be amenable to treatment with aerosols?

- Can we deliver adequate quantities of aerosol to the lungs of newborn babies, either during mechanical ventilation or during spontaneous breathing?

- Can we target specific sites in the airways and lungs?

- Are there any clinical or physiological data about acute or long term therapeutic responses to aerosol treatment in newborns?

\section{Respiratory tract disorders in the newborn} A range of respiratory tract disorders extending from the upper airway to the pulmonary vasculature is potentially accessible to treatment with aerosols. For a few there is clinical evidence of efficacy. $\beta$ Agonist bronchodilators and anticholinergic agents are effective in mechanically ventilated and freely breathing young infants. ${ }^{1}$ The management of subglottic oedema (with nebulised adrenaline), pulmonary infection (with antiviral or antibacterial agents), airway inflammation (with anti-inflammatory agents or antioxidants), surfactant deficiency (with particulate or aerosol preparations of surfactant), and raised pulmonary vascular resistance (by inhaled pulmonary vasodilator agents), are all potential therapeutic areas.

\section{Aerosol generation}

Department of Neonatal Medicine, Royal Postgraduate Medical School, Hammersmith Hospital, DuCane Road, London W12 0NN

Correspondence to: Dr Silverman. output to respirable particles but reducing the also be used to deliver smaller particles. ${ }^{34}$ The overall rate of delivery of aerosols. ${ }^{2}$ Spacers can potential for delivering dry powder into the neonatal respiratory system has not been explored, but the use of fluidised bed technology may allow this technique to be applied to drugs which cannot be dissolved or suspended in carrier liquids.

Particle size is affected by the viscosity, density, and surface tension of the solution being nebulised. Thus the concentration of a drug in solution influences the output of a jet nebuliser, often unpredictably. Both the output and the particle size from jet nebulisers are influenced by cooling from heat lost through evaporation (up to $15^{\circ} \mathrm{C}$ ). ${ }^{5} 6$ When nebulising into a humidified ventilator circuit, a rapid increase in particle size may occur that can affect the distribution of aerosol in the lung. ${ }^{78}$ Thus the nebuliser that may seem to be ideal in a laboratory may be inadequate for clinical purposes. The importance and extent of hygroscopic increases in particle size have not been fully explored. Serious problems were highlighted in the delivery of suspended particles (such as topical steroids) within aerosols. The main problem is that the suspending fluid can be delivered without a particle so that it is not possible to predict the delivery of suspended particles either from jet nebulisers or from ultrasonic nebulisers.

Several examples from the enormous range of jet nebulisers were reviewed. ${ }^{9-11}$ There are clearly big differences in the mass output and in the frequency distribution of particle size. The risk of reducing airway temperature during nebulisation is unknown; air leak has been associated with low inspired air temperatures during neonatal intermittent positive pressure ventilation (IPPV). Ultrasonic nebulisers, though they avoid cooling, generally have a larger droplet size. Higher frequency crystals might improve this aspect of their function in the future, rendering the output more suitable for administration to infants.

In preliminary studies, metered dose inhalers coupled with spacer devices within ventilator circuits were at least as effective as jet nebulisers in adults. ${ }^{12}$ Such a system would, however, have to be triggered by the ventilator to match the output to the inspiratory phase, or be manually delivered to synchronise with inspiration. The latter approach has been used in adults in intensive care units.

The output of therapeutic aerosols has not been adequately standardised. The size distribution can be measured by several different 
methods. Light scattering devices measure the mass median diameter of droplets, and particle impactors measure the mass median aerodynamic diameter, of dry particles. Claims made for particular devices apply only to the conditions under which the testing was carried out. The important information concerned the mass and size distribution of particles tested under conditions that mimicked the therapeutic delivery of a particular agent as closely as possible. The size of particles at the time that they enter the respiratory tracts of infants should be reported. The appropriate size distribution in a therapeutic aerosol for a newborn infant is not known.

\section{Delivery into mechanical ventilator circuits}

Pressure limited, time cycled ventilators are universally used for neonatal ventilation. Unless fresh gas flow can be totally delivered through the nebuliser, constant flow during expiration imposes severe limits on the inspired concentration of therapeutic aerosols. The devices beloved of anaesthetists, which deliver preset tidal volumes, have a ready made 'holding chamber' in the inspiratory limb of the circuit that would facilitate aerosol delivery. The workshop did not consider the major problems imposed by new devices for artificial ventilation of newborns: high frequency oscillation, jet ventilators, and 'demand' devices. The precise configuration of the neonatal ventilator circuit, the type of endotracheal tube, and the fresh gas flow rate will all influence the characteristics of aerosols delivered into it.

In vitro studies using filters to assess the dose could be inaccurate. Some jet nebulisers deliver large particles. that 'rain out' in the tubing and have the potential to contaminate the filter. This would lead to an overestimate of dose delivered. Conversely, fine particles (which only represent a small proportion of dose) may behave like a gas, and would be exhaled. If these were trapped by the filter then again the dose estimates from filter studies might be too high. Filters have been used to estimate the delivered dose. ${ }^{13}$

Adult rabbits (either alive or freshly killed) have been used to assess the quantity and distribution of aerosol delivered to the lungs from neonatal ventilator circuits. ${ }^{13-16}$ The limitations of this model are that the lungs are usually normal and that the pattern of airway branching differs from that of human airways. The model has shown that droplets of less than 3.5 $\mu \mathrm{m}$ mass médium diameter and latex particles of less than $2 \mu \mathrm{m}$ have an essentially peripheral distribution within the rabbit lung. Aerosol is more effective than an equivalent dose of a drug delivered directly into the endotracheal tube and both the tidal volume and the inspiratory:expiratory ratio (which affects the residence time within the lung) influence the dose of aerosol deposited in the lung. ${ }^{16}$ For a constant flow circuit as little as $1-2 \%$ of the generated aerosol may be deposited within the lung of a rabbit. ${ }^{14}{ }^{16} \mathrm{By}$ bolus or timed aerosol delivery into the circuit, the effective dose may be enhanced significantly.
For instance, up to $10 \%$ of the generated aerosol can be delivered using intermittent treatment by dosimeter, timed to coincide with inspiration ( $\mathrm{K}$ Nikander, personal communication). ${ }^{13}$ A newly devised mechanical ventilator, which has a low, continuous, fresh gas flow rate and therefore allows a higher concentration to build up in the circuit also increased delivery twofold to threefold-even with continuous nebulisation-compared with a traditional constant flow infant ventilator (J Grigg, personal observations). ${ }^{17}$

Dosimetric techniques to increase the proportion of drugs delivered to the baby have enormous potential for error unless the circuit is precisely characterised. The start up time of jet nebulisers needs to be taken into account. The precise location of the nebuliser in the circuit, the timing of the jet, and the gas flow rate, are critical. The potential exists for the infant to receive none of the drug if the timing is not accurate. By using a metered dose inhaler as a dosimeter within a circuit, a fourfold increase in the dose delivered is theoretically possible ( $M$ Dolovich, personal communication). A small holding chamber increases the delivery threefold compared with releasing the metered dose inhaler directly into the endotracheal tube through an elbow device. ${ }^{12}$

Human studies of dose delivery by aerosol are few. Radioaerosols might be valid in limited circumstances (for instance in the study of antibiotic distribution in children with cystic fibrosis) but the only non-radioactive marker that has been assessed is sodium cromoglycate, about half of which is excreted unchanged in the urine in adults. Its pharmacokinetics have not been studied in infants, but two studies of delivery of sodium cromoglycate by jet nebuliser to mechanically ventilated preterm babies with respiratory distress suggested that $0.06-0 \cdot 1 \%$ of a nominal fill of a jet nebuliser could be retrieved from the urine after 10 minutes' nebulisation (W Kelly, D Cameron, personal communications). We know of no studies of the distribution of aerosols in the lungs of newborns.

\section{Delivery of aerosol to spontaneously breathing newborns}

The factors that affect the dose and distribution of aerosol delivered by facemask to spontaneously breathing newborn infants have not been examined in vivo. In vitro measurements suggest that a number of factors may influence the dose of aerosol available for inhalation and these include particle size, the use and characteristics of a spacer (or holding chamber), the distance of the jet of aerosol from the face, the cooling effect of repeated discharges from metered dose inhalers, and the association between tidal volume and the size of holding chambers. The effect of inspiratory flow rate during tidal breathing on the dose and concentration inhaled from jet nebulisers was reported independently by two groups ( $P$ Le Souef, $M$ Everard, personal communications). Because their tidal flow rates are greater than the flow rate from the nebuliser, air entrainment by 
older children and adults dilutes the concentration of aerosol. This means that the dose delivered is the same for children of more than about $80 \mathrm{~cm}$ in length. Conversely, for infants who are too small to entrain air $(<80 \mathrm{~cm}$ length, for a jet flow of $6 \mathrm{l} / \mathrm{min}$ ) the total dose inhaled will diminish, but the inspired concentration of aerosol will be the same as the nebuliser output, and therefore greater than for entraining subjects. ${ }^{18}$ In vivo measurements suggest that drug delivery by jet nebuliser to freely breathing young infants is negligible. ${ }^{19}$ These observations have implications for both the delivery and distribution of therapeutic aerosols and for testing of bronchial responsiveness in infants.

\section{Side effects of inhaled drugs}

Little is known about the effects of inhaled drugs on the newborn lung, either in the short or long term. Bronchoconstriction has been reported in wheezy infants receiving hypoosmolar solutions as well as solutions with low pH. Metered dose inhalers contain chlorofluorocarbons and surfactants, which have adverse effects in animals and in some adult volunteers and which are ecologically sensitive. Preservatives may cause damage to cilia, sometimes permanently. Concern was expressed about the possible effects of high concentrations of corticosteroids on the growing lung, but no information was available. Finally, with the evidence that low ventilator circuit temperature may be associated with pneumothorax in newborn babies, the cooling effect of jet nebulisers must be considered to be a potential risk.

\section{Clinical studies}

Short term double blind clinical trials of inhaled sodium cromoglycate solution and inhaled topical steroids (budesonide suspension) are under way in three centres, but no results are available yet. In addition single dose clinical studies of inhaled steroids administered by jet nebuliser to mechanically ventilated infants, infants ventilated by tracheostomy, and spontaneously breathing babies have been reported. Bearing in mind that the output of particulate suspensions varies among different types of jet nebuliser, it is not certain whether observations made from uncontrolled studies can be evaluated. $^{20}$

\section{General conclusions}

(1) The group felt that it was important to measure both the droplet size presented to the respiratory tract (bearing in mind the effects of humidification) and the dose that reaches the lung by an appropriate technique yet to be devised. This would depend on radioaerosols, or adequate kinetic studies of drugs such as sodium cromoglycate.

(2) The distribution of drug within the lungs should be studied either in animal models, which have inevitable anatomical limitations and pathological differences, or by using radioaerosols, which raises ethical problems.

(3) It is important to make appropriate in vitro measurements using the precise aerosol generating device, drug (in its correct concentration), and ventilator circuit, to estimate the dose delivered before undergoing any clinical trials using aerosols in the newborn. The ideal delivery system (jet nebuliser, dosimeter, or ultrasonic nebuliser) has not been determined.

(4) The technical problems of delivering suspended particles by aerosol need urgent solution in view of clinical demand for topical steroid treatment by aerosol in newborns.

Report prepared by Michael Silverman on behalf of the ollowing active participants in the workshop: Duncan Cameron, UK, Magnus Dahlback, Sweden, Myrna Dolovich, Canada, Michael Dunn, Canada, Mark Everard, UK, Jonathan Grigg, UK, Arja Hakulinen, Finland, Kirsti Heinonen, Finland, William Kelly, USA, Peter Le Souef, Australia, Magnus Lindroth, Sweden, Shirley Murphy, USA, Kurt Nikander, Sweden, Chris O'Callaghan UK, Noell Snell, UK.

We thank Fisons UK for their support.

1 Wilkie RA, Bryan MH. Effects of bronchodilators on airway resistance in ventilator-dependent neonates with chronic lung disease. $\mathcal{f}$ Pediatr 1987;111:278-82.

2 Byron PR, Dalby RN, Hickey AJ. Optimized inhalation of aerosols. I. The effects of spherical baffle size and position upon the output of several pressurized nonaqueous suspension formulations. Pharmaceutical Research 1989;6: 225-9.

3 Newman SP, Millar AB, Lennard-Jones TR, Moren F, Clarke SW. Improvement pf pressurised aerosol deposition with nebuhaler spacer device. Thorax 1984;39:935-41.

4 Zainudin BMZ, Biddiscombe $M$, Tolfree SEJ, Short $M$, Spiro SG. Influence of size and inspiratory flow rates on the efficiency of a spacer: in vitro study. Thorax 1988;43:815.

5 Clay MM, Newman SP, Pavia D, Lennard-Jones TR, Clark SW. Assessment of jet nebulisers for lung aerosol therapy. Lancet 1983;ii:592-4.

6 O'Callaghan C, Clarke AR, Milner AD. Inaccurate calculation of drug output from nebulisers. Eur $\mathcal{J}$ Pediatr 1989;148: $473-4$.

7 Yu CP, Xu GB. Deposition of hygroscopic particles in growing human lungs. In: Hofmann W, ed. Deposition and growing human lungs. In: Hofmann W, ed. Deposition and clearance of aerosols in

8 Ferron GA, Kreyling WG, Haider B. Inhalation of salt aerosol particles. II Growth and deposition in the human respiratory tract. Foumal of Aerosol Science 1988;19:611-31.

9 Ahrens RC, Ries RA, Popendorf W, Wiese JA. Delivery of therapeutic aerosols through endotracheal tubes. Pediat Pulmonol 1986;2:19-26.

10 Dahlback $M$, Nerbrink O, Arborelius M, Hansson HC Output characteristics from three medical nebulisers. fournal of Aerosol Science 1986;17:563-4.

11 Cameron DC, Clay M, Silverman M. Evaluation of nebulisers for use in neonatal ventilator circuits. Crit Care Med 1990 (in press).

12 Fuller HG, Dolovich MB, Posmituk G, Wong-Pack W, Newhouse MT. Pressurised aerosol versus jet aeroso delivery to mechanically ventilated patients. Am Rev Resp Dis 1990;141:440-4.

13 Dahlback M, Wollmer P, Drefeldt B, Jonson B. Controlled aerosol delivery during mechanical ventilation. Foumal of Aerosol Medicine 1989;2:339-47.

14 Flavin M, Dolovich M, MacDonald M, O'Brodovich, Coates G. Aerosol delivery to the rabbit lung with an infant G. Aerosol delivery to the rabbit lung
ventilator. Pediatr Pulmonol 1986;2:35-9.

15 Dahlback, Nerbrink O, Wollmer P, Karlberg IB, Prytz M. Deposition of tracer aerosols in the rabbit respiratory tract. Fournal of Aerosol Science 1987;18:733-6.

16 Cameron D, Clay M, Arnot R, Silverman M. Aerosol delivery into neonatal ventilator circuits: a rabbit model. Pediat Pulmonol 1990 (in press)

17 Chan KN, Chakrabarti MK, Whitwam JG, Silverman M. Assessment of a new valveless infant ventilator. Arch $D$ is Child 1988;63:162-7.

18 Le Souef PN, Collins GG, Cole CH. Dilution of aerosol by air entrainment in children. Aust N Z F Med 1989;19:659.

19 Salmon B, Wilson NM, Silverman M. How much aeroso reaches the lungs of wheezy infants and toddlers? Arch Dis Child 1990;65:401-3.

20 Berg E, Backstrom K, Dahlback M, Nerbrink O. Output and particle size distribution of pulmicort suspension generated from MAD2 and Pariboy jet nebulisers. Fournal of Aerosol Science 1988;19:1093-6. 